SERTA ROMANICA

FESTSCHRIFT FÜR GERHARD ROHLFS 


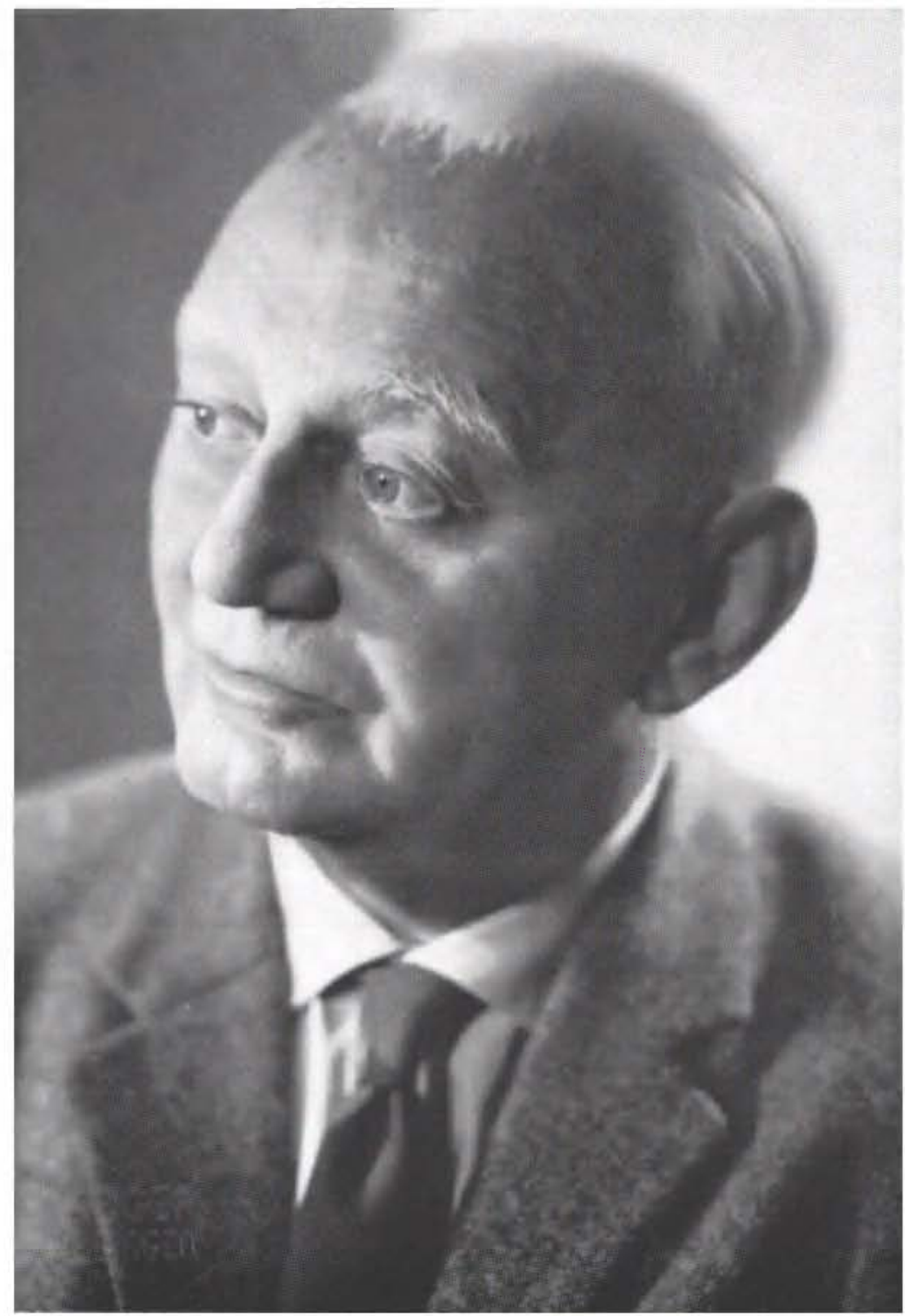

G. Rohlf. 


\title{
SERTA ROMANICA
}

FESTSCHRIFT

FUR

GERHARD ROHLFS

ZUM

75. GEBURTSTAG

\author{
Im Einvernehmen mit \\ W. Theodor Elwert und Heinrich Lausberg \\ herausgegeben von \\ Rudolf Baehr und Kurt Wais
}

MAX NIEMEYER VERLAG TUBINGEN 
(c) Max Niemeyer Verlag Tübingen 1968

Alle Rechte vorbehalten - Printed in Germany

Satz und Druck: H.Laupp jr Tübingen

Einband von Heinr. Koch Tübingen 
ET VIRIDI IN CAMPO

TEMPLUM DE MARMORE PONAM.

Georgica III,13

\section{Hochverehrter Meister und Kollege!}

Selbstzufriedene Rückschau ist Ihrem unermüdlich nach vorwärts, auf stets neue und tiefere Erkenntnis gerichteten Wesen fremd. Wir möchten Ihnen daher einen Vergil-Vers widmen, der - selbst jenem hohen Preislied auf das Tun des Menschen entnommen - nach Art einer Devise in einer einzigen Zeile Dynamik, Wesen und Besonderheit Ihres Schaffens zu umgreifen scheint. Ihr starkes Wollen und Thr sicheres, in stetem Fortgang begriffenes Vollbringen finden in der Doppelbedeutung der Futurform ihren sprachlichen Ausdruck. Sich selbst als plein-air-Romanisten verstehend haben Sie schon als blutjunger Student, sodann als langjähriger Mitarbeiter des AIS und seither in ungezählten Forschungsreisen die romanische Sprachwissenschaft aus einem bloßen Retortendasein in den Gelehrtenstuben hinausgeführt auf den viridis campus, der sich Ihrer "Conquistadorennatur" (Jaberg) von Griechenland und Rumänien bis an die Westküste der Iberischen Halbinsel dehnt. Auf diesem immer grünenden Felde der unmittelbaren Sprachwirklichkeit hatten und haben sich für Sie alle Theorien, Thesen und Spekulationen zu bewähren. So wurden Sie in einem wissenschaftsgeschichtlich bedeutsamen Moment zum Künder eines recht verstandenen, lebensvollen „Positivismus" in der Auseinandersetzung mit der ,idealistischen Neuphilologie“, deren grundsätzliche Fragestellung Sie in ihrer Berechtigung nie angezweifelt haben, deren vorschnelle Schlußfolgerungen und sachlichen Unrichtigkeiten Sie aber im Dienste der Sache zurückweisen mußten. Ihre mit Selbständigkeit, Konsequenz und Strenge entwickelte Methode, die Fülle verifizierten Wissens und eine glückliche Kombinationsgabe machten Sie zu einem entscheidenden Beförderer der romanischen Dialektologie, deren überragende Bedeutung für die romanische Sprachwissenschaft des 20. Jahrhunderts außer Zweifel steht. Auf diesem weiten Feld haben Sie ein Werk aufgerichtet, das sich uns wie ein Tempel Ihrer geliebten Magna Graecia darstellt: durchflutet von Licht und Luft, noch im kleinsten Einzelteil sinnvoll auf die Harmonie des Ganzen bezogen, der Zeit und der Mode trotzend.Wer kennte nicht die mächtigen Säulen - Ihre opera magna, 
die Ihre Bibliographie in so imponierender Zahl ausweist - und wer sähe nicht die Hand des Meisters in jedem einzelnen Zug?

Die verdiente Anerkennung für Thre Arbeit blieb nicht aus. Sie rückten auf dem Lehrstuhl Karl Vosslers nach und nehmen Benedetto Croces Sessel in der K. Schwedischen Akademie der Wissenschaften ein. Athen, Palermo und Turin haben Ihnen die Würde des doctor honoris causa verliehen, bedeutende Akademien und gelehrte Gesellschaften haben Sie zu ihrem Mitglied oder Ehrenmitglied gewählt, verschiedene Staaten haben Sie mit hohen Orden für wissenschaftliches Verdienst ausgezeichnet, mehrere Städte Süditaliens haben Sie zu ihrem Ehrenbürger gemacht; die Fachwelt ehrte Sie zu Ihrem 60. Geburtstag mit einer Tabula gratulatoria, zu Ihrem 65. mit einer Festschrift.

Mit Bewunderung, Stolz und Dankbarkeit gedenkt Ihrer auch heute die romanische Philologie in aller Welt und mit ihr ungezählte ehemalige Studenten in Tübingen und München, denen Sie akademischer Lehrer und leuchtendes Vorbild eines gelebten Wissenschaftsethos waren und sind. Die Zahl derer, die sich Ihnen verbunden fühlen, überschreitet so sehr die technischen Grenzen einer Festschrift, daß sich die Herausgeber von vorn herein auf den Grundsatz einer nur andeutungsweisen Stellvertretung zurückziehen mußten. Und wenn wir allen Beiträgern zu danken haben, so müssen wir alle anderen, die nicht eingeladen werden konnten, ebenso herzlich um ihr gütiges Verständnis für die uns gezogenen Grenzen bitten. Eine thematische Beschränkung schien im Hinblick auf den zu Ehrenden nicht gerechtfertigt, da er ja geradezu die Verkörperung der Weite unseres Faches ist. Daß die sprachwissenschaftlichen Beiträge überwiegen, ist selbstverständlich; ebenso selbstverständlich ist es aber auch, $\mathrm{da} ß$ Literatur und Volkskunde in einer Rohlfs-Festschrift vertreten sind. H.Lausbergs Vertonungen evozieren den Jubilar als Gründer und Protektor romanischer Chöre, mit denen sich für alle einst Beteiligten, nicht zum wenigsten für Sie als den Initiator selbst, viele schöne Erinnerungen verbinden.

Es bleibt den Herausgebern zum Schluß, all denen wärmstens zu danken, die das Zustandekommen dieser Festschrift ermöglichten, ganz besonders Herrn Verleger Robert Harsch-Niemeyer, der mit ebenso raschem wie freudigem Entschluß die Drucklegung des Buches übernahm.

Stellvertretend für alle Ihre Freunde und zusammen mit unseren allerbestenWünschen legen wir, verehrter Meister, diese Festschrift als Zeichen unseres Dankes und unserer Verbundenheit in Ihre Hände.

Die Herausgeber 